\title{
Testing and unpacking the effects of digital fake news: on presidential candidate evaluations and voter support
}

\author{
Rodolfo Leyva ${ }^{1} \cdot$ Charlie Beckett $^{2}$
}

Received: 22 December 2019 / Accepted: 13 April 2020 / Published online: 12 May 2020

(c) The Author(s) 2020

\begin{abstract}
There is growing worldwide concern that the rampant spread of digital fake news (DFN) via new media technologies is detrimentally impacting Democratic elections. However, the actual influence of this recent Internet phenomenon on electoral decisions has not been directly examined. Accordingly, this study tested the effects of attention to DFN on readers' Presidential candidate preferences via an experimental web-survey administered to a cross-sectional American sample $(N=552)$. Results showed no main effect of exposure to DFN on participants' candidate evaluations or vote choice. However, the perceived believability of DFN about the Democratic candidate negatively mediated evaluations of that candidate-especially amongst far-right ideologues. These results suggest that DFN may at worst reinforce the partisan dispositions of mostly politically conservative Internet users, but does not cause or induce conversions in these dispositions. Overall, this study contributes novel experimental evidence, indicating that the potential electoral impact of DFN, although concerning, is strongly conditional on a reciprocal interaction between message receptibility and a pre-existing right-wing ideological orientation. The said impact is, therefore, likely narrow in scope.
\end{abstract}

Keywords Fake news $\cdot$ Priming $\cdot$ Framing effects $\cdot$ Voting $\cdot$ Candidate preferences

\section{Introduction}

Following the 2016 Presidential election victory of Donald Trump, several journalists and politicians argued that the widespread circulation of digital fake news (DFN) via new media technologies played a decisive role in influencing votes and turnout (Mustafaraj and Metaxas 2017; Tandoc et al. 2017). This notion has been given further credence by accusations from American intelligence officials that the Russian government honed and sponsored a sophisticated bombardment of DFN through Facebook and Twitter to sway the election in Trump's favor. These factors have thus stoked public concern over the possibility that DFN can now be used as an effective weapon to undermine democratic elections across the globe (Vargo et al. 2018). ${ }^{1}$

Rodolfo Leyva

r.leyva@1se.ac.uk

Charlie Beckett

c.h.beckett@1se.ac.uk

1 London School of Economics and Political Science, London, UK

2 Department of Media and Communications, London School of Economics and Political Science, London, UK
Consequently, governments and media companies are developing high-tech algorithmic counter-measures to mitigate the spread of political DFN campaigns (Nelson and Taneja 2018). For example, Facebook and Twitter have purported that they have enhanced their machine learning protocols to better detect and remove DFN accounts and postings (Haciyakupoglu et al. 2018).

However, these concerns and pre-emptive responses are currently mostly grounded on speculation rather than substantiated empirical evidence. That is, and due largely to the relative recency of this phenomenon, whether DFN can actually and negatively affect people's attitudes towards and decisions to vote for a politician running for office has yet to be empirically tested let alone confirmed. To date, and while highly insightful, the few available scientific studies on DFN have mostly either only looked at the spread and usage of DFN during the 2016 US Presidential election (e.g., Guess et al. 2018; Nelson and Taneja 2018), or examined factors that increase a reader's receptivity to DFN messages (e.g., Allcott and Gentzkow 2017; Pennycook et al. 2017).

\footnotetext{
${ }^{1}$ Relatedly, the use of concerted DFN campaigns was observed in, amongst other democratic electoral contexts, the lead up to the UK's referendum to leave the European Union and 2016 municipal elections in Brazil (Arnaudo 2017).
} 
Therefore, to help fill this empirical gap, the present online survey experiment tested the direct effects of exposure to DFN on evaluations of and intentions to vote for two major US Presidential candidates. Furthermore, this experiment additionally tested for indirect media effects by examining mediated relationships and interactions between DFN exposure, the perceived believability of DFN, and partisan ideology. In doing so, this study helps to address the need for more complex conceptualizations of and research on how pertinent reading contexts and individual characteristics can mediate and/or moderate news media's capacity to affect attitudes and behaviors (Borah 2011, Newton 2019; Slothuus and De Vreese 2010). Accordingly, the article proceeds as follows. First, we review the relevant political communications literature and DFN research that informed this study's theoretical foundations and hypotheses. Next, we discuss this study's methods, findings, contributions, and limitations.

\section{Theorizing the potential attitudinal effects of DFN}

DFN is generally defined in the literature as non-satirical and deliberately fabricated news stories that are designed to appear credible, and disseminated through the Internet to generate advertising revenue and/or influence people's politics (Guess et al. 2018; Haciyakupoglu et al. 2018; Nelson and Taneja 2018; Tandoc et al. 2017). Whilst this is perhaps an overly broad definition, it is important to note that, as Vargo et al. (2018) argue, DFN is not the same as "bad reporting and ideologically driven news that is uncongenial to one's views" (p. 2031). Furthermore, DFN stories are typically full-fledged articles from dedicated host websites that are largely distributed through prominent social networking sites such as Facebook and Twitter. Although, DFN can also take the form of organized 'Twitter bombs' (i.e., postings of numerous Tweets with the same or similar content from multiple accounts). Additionally, DFN content usually contains eye-catching headlines, provocative imagery, and defamatory accounts about a person, group, or event. In the specific context of government elections, DFN articles or social media posts tend to feature demonstrably false claims about a candidate or party's supposed policy positions, corruption, criminal activities, biases, discriminatory intents, or legislative agenda (Mustafaraj and Metaxas 2017; Pennycook et al. 2017). Hence, political DFN content is effectively honed clickbait that is intentionally framed to sway people's sociopolitical thoughts and practices by appealing to their emotions and sense of indignation (Nelson and Taneja 2018; Vargo et al. 2018).

This naturally raises the question: can DFN actually influence a reader's attitudes towards and decision to vote for a given candidate? As stated earlier, this question has yet to be directly tested, but the extensive media framing and priming literature offer applicable insights that point to a couple of plausible answers. For example, studies have shown that exposure to negative and sensationalistic wording and imagery, such as those commonly found in political attack ads or tabloid headlines, capture attention, and stimulate emotional reactions more strongly than neutral stimuli. The combination of these elicited affective and cognitive reactions mediates what information is believed and learned (Gibbons et al. 2005), which may then affect candidate evaluations and voting intentions (Balmas and Sheafer 2010; Chang 2001). To elaborate, exposure to emotionalized media content can concurrently activate frame-consistent memory associations and emotions. This then leads "to an intensification of the mood state; rendering mood-related thoughts and memories more accessible than unrelated cognitions" (Baumgartner and Wirth 2012, p. 5). As a consequence, fewer cognitive resources are left available for the processing of peripheral or discordant information; making it difficult to counterargue and not be implicitly influenced by the intended media message (Arendt 2013; Matthes and Schmuck 2017). Ergo, the more a news story's presentation of information induces fear, anger, contempt, or anxiety, the more its message can subliminally inflect a reader's opinions of and support for certain candidates and their policy platforms (Brader et al. 2004; Seate and Mastro 2017). In light of this research, and taking into account that political attack ads and tabloid articles are arguably the precursors to, and are, in many ways, similar in terms of content presentation style and tone as, DFN, then one can reasonably draw the conclusion that DFN has at least the potential to negatively affect electoral-related attitudes and decisions.

That said, several studies also show that the effects of news media on political opinions and behaviors, in particular, are strongly dependent on several situational reading contexts and individual-level characteristics (Feldman 2011; Haider-Markel and Joslyn 2001; Matthes and Schmuck 2017). Of these varying moderating and mediating factors, the most relevant to the present study are news message believability and partisanship. The importance of the former factor is fairly straightforward. Put simply, if a reader accepts a political news message as accurate and credible, then the likelier it is that the presented information will become encoded and utilized to interpret and evaluate a subsequently encountered and related attitude object. Conversely, the less the message is trusted, the less likely it is to inform a reader's beliefs and judgments (Miller and Krosnick 2000; Moy et al. 2016). However, the extent to which readers believe or disbelieve political news information can be additionally contingent on the direction and extremity of their partisanship (Arpan and Raney 2003; Newton 2019). 
To wit, if a political news article's source cues or issue framings are recognized as trustworthy and congruent with perceiver political predispositions, then the higher the probability is that its information will be uncritically accepted and vice versa (Arpan and Raney 2003; Haider-Markel and Joslyn 2001; Moy et al. 2016). Two leading explanations for this, respectively, posit that: (1) people are cognitive misers. Therefore, to save time and mental energy, they avoid effortful and controlled reasoning; preferring instead to rely on peripheral information and heuristics to make quick evaluations and decisions. (2) People are also inclined to hold on to and rationalize their firm and long-held beliefs when faced with counter-attitudinal information - a phenomenon known as motivated reasoning. ${ }^{2}$ These cognitive and psychological tendencies mean that rather than carefully weigh and examine the argumentative merits and evidence of a political news report, readers will normally form immediate conclusions based largely on the extent to which the available source cues and message frames align with their existing ideological orientations and preconceptions. This is especially the case for hyper-partisan readers (Newton 2019; Slothuus and De Vreese 2010). Of course, instances of political news exposure-irrespective of the presented information's veracity-may, in some cases, lead to changes in the valence and content of a reader's existing memorystored schema networks and associations (Lecheler and De Vreese 2011). Nevertheless, most instances of news exposure usually result in a bias towards reinforcing rather than converting pre-established beliefs and opinions (Igartua and Cheng 2009; Igartua et al. 2012).

Correspondingly, a parallel body of selective-exposure research shows that people prefer and spend more time reading online news content with opinion-reinforcing over opinion-challenging information. These news attention and consumption habits thus only serve to solidify readers' political identities (Garrett 2009; Graf and Aday 2008; Knobloch-Westerwick and Meng 2011). Coincidently, the few studies on DFN also seem to indicate that exposure to DFN has at most a reinforcing effect on readers' candidate preferences. A survey study by Allcott and Gentzkow (2017), for example, found that in the 2016 US election, people were considerably more likely to believe DFN that favored their preferred candidate. Other studies further show

\footnotetext{
${ }^{2}$ Heuristic processing and motivated reasoning, respectively, entail Type-1 (e.g., fast and automatic) and Type-2 (e.g., slow and deliberate) modes of information-processing. Despite these differences, both processes can work to reinforce established beliefs and attitudes. Specifically, heuristic processing is often activated when encountering congruent information (Igartua and Cheng 2009). Motivated reasoning tends to be activated when encountering incongruent information that induces cognitive dissonance, which is then often resolved by actively rationalizing one's existing beliefs and/or attitudes to maintain cognitive consistency (Petersen et al. 2013).
}

that during this election, DFN audiences were very small and highly concentrated (Nelson and Taneja 2018), with nearly six out of ten visits to DFN sites (the majority of which were politically conservative), coming from $20 \%$ of the most right-wing online users (Guess et al. 2018). Relatedly, robust experiments conducted by Pennycook and Rand (2019) showed that the overall capacity to discern Republican-consistent or Democrat-consistent real from fake news was lower among participants who supported Donald Trump over Hillary Clinton, relative to those who supported Clinton over Trump. As can be inferred from Pennycook and Rand's (2019) arguments, a plausible reason for these curious outcomes is that conservative participants automatically drew on their pre-existing partisan schemas and corresponding gut feelings to heuristically judge the accuracy of the DFN headlines which they were exposed to. Liberal participants, on the other hand, tended to engage in analytical thinking, which enhanced their ability to deliberate on and accurately ascertain the truthfulness of the presented DFN claims.

When considered together, the existing research on media effects and DFN hence raises doubts as to whether DFN can affect changes in people's candidate attitudes and corresponding voting behaviors. More to the point, the studies outlined above indicate that attention to DFN at most reifies audiences' pre-existing partisan attitudes and voting intentions, and only if this DFN features attitude-consistent information. Exposure to counter-attitudinal DFN is, therefore, unlikely to induce conversions in reader's candidate preferences. Furthermore, these reinforcement effects may be stronger for right-wing than for left-wing readers. To reiterate, this is because when faced with persuasive political appeals and relative to liberals, conservatives are more prone to employing heuristic over systematic information-processing and be implicitly persuaded via evaluative conditioning (Jost and Krochik 2014). Conservatives also generally limit their exposure to novel stimuli and are likelier to accept the credibility of and spread and attend to DFN (Guess et al. 2018; Mele et al. 2017; Pennycook and Rand 2019). In tandem, these cognitive and behavioral traits can reduce conservatives' information gain and "probability of correcting invalid assumptions of negativity", which can lead them to hold a "greater number of negative attitudes [..] than liberals" (Shook and Fazio 2009, p. 2). Consistent with all these empirical observations, conservatives should be more credulous towards DFN about a candidate from a rival party than their counterparts. This combination of fake news message receptibility and right-wing ideology may then generate an interaction effect potent enough to significantly lower the evaluation and likelihood of voting for a said rival candidate. Hence, based on everything discussed so far, the following hypotheses are proposed and tested in the American context. 


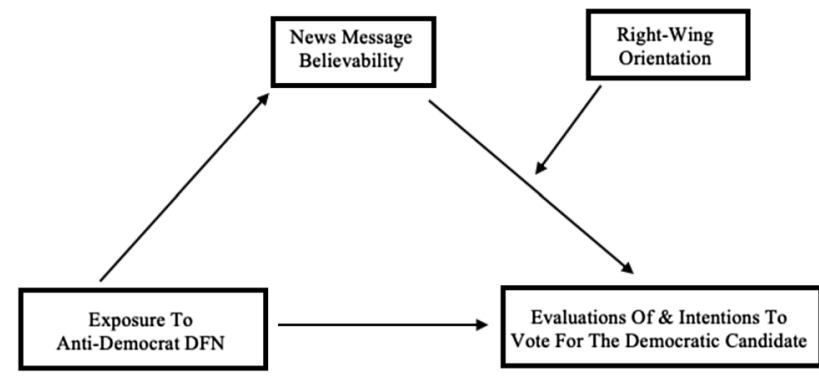

Fig. 1 Hypothesized conditional process model (right-wing orientation refers here to both economically and socially conservative ideological leanings)

(H1) Exposure to DFN about a Democratic or Republican Presidential candidate (as compared to exposure to neutral news stimuli) will, ceteris paribus, have no direct effect on evaluations of nor on intentions to vote for the respective candidate.

(H2) The perceived believability of anti-Democrat DFN will be higher for conservatives than for leftists. (H3) The perceived believability of anti-Republican DFN will not significantly differ by partisan orientation. Put differently, leftists will be no more likely than conservatives to accept the claims of anti-Republican DFN content.

(H4) In participants exposed to anti-Democrat DFN (as compared to those exposed to neutral news stimuli), the interaction between news message believability and partisan orientation will lead to decreases in the opinions of and voter support for the Democratic candidate-particularly amongst participants with right-wing orientations (see Fig. 1).

(H5) In participants exposed to anti-Republican DFN (as compared to those exposed to neutral news stimuli), the interaction between news message believability and partisan orientation will have no effect on the opinions of or voter support for the Republican candidate, i.e., in these contexts, no significant differences will be observed between leftists and conservatives.

\section{Methodology}

This study utilized a between-subject experimental websurvey design (treatment vs. control), with two treatment conditions. Participants were first presented with an online consent form that masked the purpose of the study as a test on whether people's online reading habits, attention spans, and information retention differed by demographic characteristics. Following this, they filled in pre-test demographic, political psychographic, and media consumption measures. They were then randomly assigned to either a (1)
anti-Clinton DFN treatment condition, (2) anti-Trump DFN treatment condition, or (3) control condition, and exposed to study materials via a questionnaire packet with the outcome measures presented at the end of the survey.

\subsection{Participants}

The surveying agency Qualtrics was commissioned to recruit participants during February 2018. Data were collected from 552 American residents aged 25-49 $(M=36.3$, $\mathrm{SD}=6.9$ years). Participants from these ages were selected, because they are likelier to vote than younger cohorts (Castillo 2016), and more likely to use new media than older cohorts. As such, they provide an arguably ideal vantage point from which to gage the potential effects of DFN on electoral decisions. The sample was $48.6 \%$ (female) and $51.4 \%$ (male), and $78.1 \%$ (White), $8 \%$ (African-American), 6\% (Latino/Hispanic), 6.5\% (East Asian), and 1.4\% (Other). Moreover, 3.3\% reported having received a (high-school education or less with no diploma), $34.4 \%$ had a (highschool diploma or GED), $12.3 \%$ had an (Associate of Arts degree), 33.5\% had a (Bachelor's degree), and 16.5\% had a (Master's degree or higher). Additionally, $11.1 \%$ reported having an annual family income of between $(0-\$ 20,000)$; with $22.8 \%$ reporting $(\$ 20,001-\$ 40,000), 21 \%$ reporting (\$40,001-\$60,000), $17.2 \%$ reporting $(\$ 60,001-\$ 80,000)$, $10.7 \%$ reporting $(\$ 80,001-\$ 100,000)$, and $17.2 \%$ reporting (\$100,001-over).

\subsection{Procedure}

In all, 184 participants were randomized into the anti-Clinton DFN condition, 167 into the anti-Trump DFN condition, and 201 into the control condition. Following their randomization, participants completed three reading tasks that were disguised as attention-memory tests and presented across the questionnaire in between several filler items. Before each task, a pop-up note informed participants that they would be shown random social media news feed posts or online news articles, and then asked a question on what was displayed. Participants were asked three post-task questions, and those who answered any of these questions incorrectly had their sessions automatically ended and data deleted. This admittedly strict protocol was taken based on three important methodological considerations. First, unlike in a standard laboratory experiment, researchers conducting web-survey experiments cannot control external distractions or be certain that participants are sufficiently engaging with the presented tasks. Second, as Maniaci and Rogge (2014, p. 75) argue, "inattentive participants might not be affected by text-based manipulations, potentially adding error variance to the effects and thereby obscuring meaningful results". Third, inattentive responding can adversely affect statistical 
analyses and generate spurious results (Maniaci and Rogge 2014). The aforementioned protocol, therefore, helps to ensure that the data set was comprised of participants who evidenced adequate news stimuli encoding. We deemed meeting this condition critical, so that in the event of finding significant treatment effects, we could be more confident that these stemmed from attention to the experimental stimuli materials.

Accordingly, for the first task, participants were instructed to read two Facebook news feed posts (each displayed separately). For the second and third tasks, participants read a short online news article. Additionally, participants were later in the questionnaire shown an additional Facebook newsfeed post that was displayed for $5 \mathrm{~s}$. This served to further prime participants in the treatment conditions with either negative framings of Clinton or Trump. In all, every participant attended to two short news articles and three Facebook posts. Finally, the stimuli materials were displayed in between 18 distractor questions. This design was implemented to help mask the purpose of the study and minimize demand effects.

\subsection{Stimuli materials}

The treatment stimuli consisted of DFN materials about Hillary Clinton and Donald Trump, because they are the most recent major US Presidential candidates to date. Trump will also very likely run for re-election in 2020, and Clinton continues to flirt with the possibility of running again. However, in any event, experimental exposure to anti-Clinton and anti-Trump DFN can shed light on how DFN may potentially affect upcoming elections. Moreover, we followed the ecological approach of a related study by Pennycook et al. (2017), which entailed using actual DFN. More specifically, the DFN stories which we used for the three reading tasks in each of the treatment conditions were selected from and have been identified as fake news by the fact-checking website Snopes.com. However, we completely made up the DFN Facebook posts used as the final priming stimuli in the treatment conditions (viz., the ones displayed for $5 \mathrm{~s}$ ), to introduce new DFN information to participants.

All of the anti-Clinton and anti-Trump DFN Facebook posts featured images of the candidates appearing dour and surly along with sensationalistic headlines. These include for example, (Hillary Caught On Tape Laughing About Irma "Wiping Out All Of Those Florida Hillbillies"), and (Trump To Deport California Democratic State Senator's Family Because They Are "All Illegals"). The anti-Clinton DFN short online articles featured libelous headlines and detailed reports of Clinton's fabricated ridicule of Hurricane Irma victims and involvement in a pay-to-play scheme. The anti-Trump DFN short online articles presented defamatory headlines and respectively detailed reports of Trump's fabricated executive order for mass deportations of undocumented immigrants and ratification of a tax bill that would negatively impact firefighters, first-responders, and unions. Additionally, all DFN materials were made to resemble realistic Facebook news feed posts or website articles to enhance ecological validity. The dates of these materials were also changed to the week of recruitment, and their displayed popularity metrics were bolded and increased to make the posts and articles appear recent and popular, and thus ostensibly more credible.

Furthermore, since the two treatment conditions contained distinct sets of DFN about opposite candidates, their potential main effects are on different target attitudes, and hence cannot be compared with each other. There is also a possibility that differences in perceptions of DFN believability could result from the anti-Clinton DFN materials being more or less convincing than the anti-Trump ones, despite both sets being equally partisan. Therefore, we created a control condition consisting of three Facebook news feed posts and two web-articles collected from legitimate press outlets that included Rolling Stone and NBC News. These materials featured non-political real news headlines and reports about sports, music, and a contaminated lettuce scare (see "Appendix" for examples of the materials used for each condition).

\subsection{Outcome measures}

\subsubsection{Candidate evaluations}

Using a six-point forced-choice response scale $(1=$ very negative, $6=$ very positive), participants were asked to indicate their "opinion/impression" of two major Democrats [sc., Hillary Clinton, Barack Obama) and two major Republicans [sc., Donald Trump, Paul Ryan]. The average was $(M=3.1$, $\mathrm{SD}=1.7)$ for Clinton and $(M=2.8, \mathrm{SD}=1.8)$ for Trump.

\subsubsection{Candidate voter choice}

Participants were asked: "If you could vote for President today, which one of the following options would you choose?", and presented with the following response options: (1) Hillary Clinton, (2) Donald Trump, (3) Third Party Candidate (e.g., Green Party or Libertarian Party), and (4) Would Not Vote. Of these options, $34.1 \%$ of participants selected Clinton and $29.9 \%$ selected Trump. These measures were used to create two dummy variables: Votes for Clinton and Votes from Trump. It should be noted that these variables reflect measures for behavioral intentions rather than actual behaviors. Nonetheless, while certainly limited, voting intents are well established and strong predictors for voting (Gutsche et al. 2014; Vaske and Donnelly 1999). 


\subsection{Mediator and moderator variables}

\subsubsection{News message believability}

Using a six-point forced-choice response scale $(1=$ strongly disagree, $6=$ strongly agree), participants were asked to select the extent which they agreed that all of the Facebook newsfeed headlines and online news articles presented to them were (1) Credible and (2) Trustworthy. These measures were averaged to create a composite variable: $[M=3.4$, $\mathrm{SD}=1.3, r(551)=0.96, p<0.001]$.

\subsubsection{Partisan ideology}

Participants were asked to indicate how much they agreed on a six-point forced-choice response scale $(1=$ strongly disagree, $6=$ strongly agree) with six self-developed statements-three of which were reversed coded. Some of these statements included the following. "People should be responsible for paying for their own healthcare and not expect the government to fund it". "Welfare makes people lazy and unwilling to work". These measures were averaged to create a composite variable $(M=3.0, \mathrm{SD}=1.1, a=0.79)$, which denotes a left- to right-wing ideological continuum. Specifically, low, middle, and high scores, respectively, represent politically leftist, centrist, and conservative orientations. While party affiliation was measured, the composite variable above was selected as the proxy for partisanship, because it captures a more precise and nuanced measure of participants' political belief and attitudinal orientation and strength than a simple categorical party variable.

\subsection{Covariates}

In addition to the demographic variables reported earlier, the political psychographic variables below have been consistently found to modulate the impact of news media on candidate evaluations and voter support (Moy et al. 2016; Newton 2019). They were thus measured as follows and controlled for in the analyses.

\subsubsection{Political interest}

This was measured via a question on prior voting, as this is indicative of political interest. Specifically, participants were asked whether they voted in the 2016 US Presidential Election. $88 \%$ reported having voted and $12 \%$ reported that they did not vote.

\subsubsection{Party affiliation}

Participants were shown a six-item list and asked to select which political party they "most identified with and supported". $31.6 \%$ identified as Republicans, $37.3 \%$ as Democrats, $5.8 \%$ as Libertarians, $1.2 \%$ as Green, $6.7 \%$ as Other, and $17.4 \%$ as none.

\subsubsection{Political knowledge}

Participants were asked to answer five multiple choice test questions on general politics knowledge unrelated to the study. Some of these included the following: "What body of government is tasked with interpreting the constitutionality of a piece of legislation (i.e., law)?" "Which of the following sectors does the US government spend the most money on?" "What was one of the original reasons given by the Bush Administration for invading Iraq in 2003?" Correct responses were coded 1 and 0 otherwise, and then summed to create an additive index $(M=2.4, \mathrm{SD}=1.3)$.

The following media selective-consumption measures were taken to partly control for the potential recency and ceiling effects caused by DFN or DFN corrections that relate to the aforementioned treatment conditions, and that participants may have encountered prior to this experiment. Using a five-point response scale ( $1=$ never, $5=$ very often $)$, participants were asked to indicate how often they received news from the five major television news organizations ( $F o x$ News, ABC News, CBS News, MSNBC, CNN). These measures were averaged to create a composite variable for $\mathrm{Tel}$ evision News Consumption ( $M=2.8, \mathrm{SD}=0.96, a=0.81)$. Participants were also asked to indicate their weekly usage of Facebook $(M=4.1, \mathrm{SD}=1.2)$ and Twitter $(M=2.6$, $\mathrm{SD}=1.6)$. Finally, participants were asked to indicate how often they received news from Breitbart News $(M=4.1$, $\mathrm{SD}=1.2)$ and InfoWars $(M=2.6, \mathrm{SD}=1.6)$, which are possibly the most popular and prominent disseminators of political DFN (Friedersdorf 2017; Hayden 2018).

\section{Results}

Analysis of covariance (ANCOVA) tests were conducted to examine the direct effects of DFN exposure on candidate evaluations and voter support ( $\mathrm{H} 1)$, with the measured demographic, mediator-moderator, and covariates entered as controls. The first set of ANCOVA tests compared differences between the anti-Clinton DFN treatment and control groups. Results showed no significant main effect of the treatment condition on evaluations of Clinton $\left(M_{\text {treatment }}=3.12, \mathrm{SD}=1.7, M_{\text {control }}=3.15, \mathrm{SD}=1.6\right) F(1$, $384)=0.285, p=0.59$, nor on intentions to vote for Clinton $\left(M_{\text {treatment }}=0.33, \mathrm{SD}=1.4, M_{\text {control }}=0.34, \mathrm{SD}=1.4\right) F(1$, $384)=0.359, p=0.55$. The second set of ANCOVA tests compared differences between the anti-Trump DFN treatment and control groups. The results showed no significant main effect of the treatment condition on evaluations 
of Trump $\left(M_{\text {treatment }}=2.93, \mathrm{SD}=1.9, M_{\text {control }}=2.93\right.$, $\mathrm{SD}=1.8) F(1,367)=0.228, p=0.68$. nor on intentions to vote for Trump $\left(M_{\text {treatment }}=0.31, \mathrm{SD}=0.46, M_{\text {control }}=0.31\right.$, $\mathrm{SD}=0.46) F(1,367)=0.139, p=0.71$. These results are all consistent with the predictions for $\mathrm{H} 1$.

To examine whether the perceived believability of the anti-Clinton DFN messages was moderated by partisan ideology (H2), we employed Hayes' (2013) PROCESS model 1 with 5000 bootstrap estimates for the construction of $95 \%$ confidence intervals (CLs). This multiple linear regressionbased test is suitable for examining interactions between experimental independent variables and continuous independent variables. Here, anti-Clinton DFN exposure was entered as the predictor variable with the control condition functioning as the reference group (coded as $1=$ treatment condition, $0=$ control condition). Partisan ideology and news believability were respectively entered as the moderator and outcome variables, and the measured demographic and covariates were entered as controls. The interaction between anti-Clinton DFN exposure and partisanship on news believability was significant $(\beta=0.19, \mathrm{SE}=0.05$, $t=-3.91, p<0.001)$. To probe this interaction further, values of the moderator were sorted into three groups using a sample mean, as well as plus and minus one standard deviation from the mean. The three groups were represented as low, middle, and high on the moderator, which, respectively, correspond to leftist, centrist, and right-wing ideological orientations. An effect of anti-Clinton DFN exposure on news believability was significant at the low levels of partisanship $(B=-0.87$, bootstrap SE $=0.07 ;[C L]=[-1.028$, $-0.7219], p<0.001)$, middle levels $(B=-0.65$, bootstrap $\mathrm{SE}=0.05 ;[\mathrm{CL}]=[-0.7668,0.5411], p<0.001)$ and high levels $(B=-0.43$, bootstrap SE $=0.08 ;[C L]=[-0.5962$, $-0.2692], p<0.001$ ), These negative beta coefficients indicate that relative to leftists and centrists, politically conservative participants assigned to the anti-Clinton DFN treatment group were more likely to believe in the trustworthiness and credibility of the DFN materials shown to them. These results lend support for $\mathrm{H} 2$.

To test H3, we employed the same moderation procedure as above, but entered anti-Trump DFN vs. control as the predictor variable (coded as $1=$ treatment condition, $0=$ control condition). As expected, the interaction between anti-Trump DFN exposure and partisanship was insignificant $(\beta=0.01$, bootstrap SE $=0.12, t=0.0972, p=0.92)$. This suggests that leftists were no more likely than conservatives to accept the anti-Trump DFN messages as accurate. Additionally, one-way ANOVA tests conducted on the individual samples for each of the treatment groups showed that anti-Clinton DFN materials were found significantly more believable by Republicans $(M=3.09, \mathrm{SD}=1.4)$ than Democrats $(M=2.54, \mathrm{SD}=1.4), F(1,122)=4.35, p=0.03$. Furthermore, the anti-Trump DFN materials were generally but not significantly believed more by Democrats $(M=3.43$, $\mathrm{SD}=1.5)$ than Republicans $(M=3.01, \mathrm{SD}=1.5), F(1$, $117)=2.03, p=0.15$. These results are all consistent with the predictions for $\mathrm{H} 3$.

To test $\mathrm{H} 4$, a moderated-mediation test was conducted using Hayes' (2013) PROCESS macro (model 14) with 10,000 bootstrap estimates for the construction of $95 \%$ CLs. In this case, we entered anti-Clinton DFN treatment vs. control group as the predictor $(X)$, news believability as the mediator $(M)$, partisan ideology as the moderator $(V)$, and evaluations of Clinton as the dependent variable $(Y)$. All other demographic and covariate measures were entered as controls. Results showed that the expected interaction between partisan ideology and perceived news believability on evaluations of Clinton was significant $(B=0.11$, bootstrap $\mathrm{SE}=0.04$; $[\mathrm{CL}]=[0.0207,0.2048], p=0.01)$. Additionally, the test yielded a significant moderatedmediation index of -0.07 bootstrap $\mathrm{SE}=0.03$; with a $95 \%$ bootstrap $[C L]=[-0.1368,-0.0158]$. Notably, the conditional indirect effect(s) of $X$ on $Y$ were insignificant for leftists $(B=0.04$, bootstrap SE $=0.05 ;[C L]=[-0.0636$, $0.1530])$ and centrists $(B=-0.04$, bootstrap $\mathrm{SE}=0.04$; $[C L]=[-0.1325,0.0510])$, but were significant for right-wing ideologues $(B=-0.12$, bootstrap $\mathrm{SE}=0.06$; $[C L]=[-0.2429,-0.0070])$. These results can be interpreted as suggesting that following exposure to anti-Democrat DFN, conservatives were more likely to believe the DFN messages. This, in turn, significantly decreased their evaluation of the corresponding Democratic candidate. Next, we repeated this test with intentions to vote for Clinton entered as the dependent variable. Here, the expected interaction between partisan ideology and perceived news believability on intentions to vote for Clinton was insignificant $(B=-0.001$, bootstrap SE $=0.10 ;[C L]=[-0.2054$, 0.2028], $p=0.99$ ), as was the moderated-mediation index of 0.00 bootstrap $\mathrm{SE}=0.07$; with a $95 \%$ bootstrap $[C L]=[-0.1501,0.1560]$. These results lend partial support for $\mathrm{H} 4$.

To test H5, we employed the same moderated-mediation test as above (i.e., PROCESS Model 14), but entered antiTrump DFN vs. control as the predictor variable and evaluations of Trump as the dependent variable. As predicted, the interaction effect between partisan ideology and perceived news believability on evaluations of Trump was insignificant $(B=0.06$, bootstrap SE $=0.10 ;[C L]=[-0.1422,0.2691]$, $p=0.54)$, as was the moderated-mediation index of -0.06 bootstrap $\mathrm{SE}=0.10$; with a 95\% bootstrap [CL $]=[-0.2976$, 0.1322]. Additionally, the interaction effect between partisan ideology and perceived news believability on intentions to vote for Trump was also insignificant $(B=-0.19$, bootstrap $\mathrm{SE}=0.17 ;[\mathrm{CL}]=[-0.5337,0.1398], p=0.25)$, as was the moderated-mediation index of 0.20 bootstrap $\mathrm{SE}=0.18$; 
with a $95 \%$ bootstrap $[C L]=[-0.1386,0.5678]$. These results lend support for $\mathrm{H} 5$.

Finally, whilst not part of our hypotheses, we also ran a partial correlation test between partisan ideology and political knowledge across the entire sample, whilst controlling for the demographic and other covariate measures. The results showed a significant negative association, indicating that conservative participants were more likely than leftists and centrists to get lower scores on our political knowledge test $r(538)=-0.16, p<0.001)$. Conservatives were also more likely to regularly selectively consume news from Brietbart News $r(538)=0.18, p<0.001)$, and less likely to selectively consume news from mainstream television news networks $r(538)=-0.12, p=0.005)$. In the following section, we will discuss how these findings relate and help to additionally explain the empirical regularities reviewed above.

\section{Discussion}

According to extensive frame and priming theory research, the way in which news is presented (i.e., a news report's hedonic tone and message framing) may considerably shape the ways that audiences construct and/or employ their cognitive-affective schemas of a given attitude object. This can then prime and direct people's decisions on subsequent-related judgment tasks (Baumgartner and Wirth 2012; Borah 2011; Gibbons et al. 2005; Kim and McCombs 2007; Lecheler and De Vreese 2011). In relation to this, both misleading and biased news reports framed in overtly and negatively emotive messages, as well as subtle misinformation in news headlines, can affect and guide people's beliefs, attitudes, and judgments (Arendt 2013; Balmas and Sheafer 2010; Chang 2001; Ecker et al. 2014; Johansen and Joslyn 2008). Hence, given the propagandistic and emotionalized messages and tone of political DFN content, and considering the ease by which it can be spread to large numbers of people through social media, public concerns over its impact on contemporary democratic elections are certainly warranted and understandable. However, the aforementioned extensive research also consistently shows that, especially with regards to political news, media effects are largely dependent on various reading contexts and individual-level characteristics such as, in particular, news message believability and partisanship (Arpan and Raney 2003; Moy et al. 2016; Newton 2019). The aim of this study was, therefore, to first test whether everything else being equal, exposure to DFN has direct negative effects on candidate evaluations and voter support. And second, to test if the effects of this exposure are indirectly enhanced or abated via an interaction between news message believability and partisan ideology. Two distinct experimental conditions were employed, which consisted of exposure to DFN materials featuring negatively valenced emphasis frames of the recent major US Presidential candidates Hillary Clinton and Donald Trump.

Regarding our first research objective, and consistent with predictions, the findings showed that exposure to DFN had no direct effect on evaluations of or intentions to votes for either candidate. Despite our controls for regular selective consumption of popular legitimate and fake news media products, and partial introduction of novel DFN information, these null results could be due to participants already knowing that some of the claims about the candidates are false. However, it is also possible that most participants were just not fooled and thus not influenced by the DFN materials, irrespective of whether or not they had such prior knowledge. A major reason for this is that people are not blank slates, and instead come equipped with varying cognitive resources, biases, and sociopolitical influences that they can draw on to process incoming news information. This is particularly the case for people who are 25 or older (e.g., such as our participants), as by this stage, they are typically fully developed adults with crystalized political positions and belief systems. Coincidingly, the capacity for news frames and primes to induce changes in political beliefs and attitudes can be strongly shielded against by an individual's pre-existing political attitudes and level of political interest (Lecheler and De Vreese 2011; Moy et al. 2016). Indeed, and although we did not present the stats for the sake of parsimony and narrative cohesion, our ANCOVA tests repeatedly showed that partisan ideology and political interest had significant and strong main effects on candidate evaluations and voter support for both Clinton and Trump. This gives some indication that participants' political predispositions helped to mitigate the potential influence of the DFN treatment materials that did not align with their partisan orientations.

Furthermore, there is evidence that Americans on average distrust DFN sites, and the vast majority of Americans still consume and depend on the traditional press outlets for credible political news information (Pennycook and Rand 2018). This incredulity towards DFN sites and reliance on legitimate news sources can guard said audiences from the undue influence of DFN content, by, for instance, exposing them to more trustworthy and nuanced coverage of complex issues, or by disproving fake news claims (Nelson and Taneja 2018). To this point, our findings showed that the majority of participants also did not trust the accuracy of the DFN materials which they were shown. The majority of participants also did not trust the accuracy of the DFN materials which they were shown. All this suggests that, on average, just because people are exposed to DFN does not mean that they will gullibly accept these as true, or that they are not also exposed to real news which can push them to question the veracity of the DFN information. Additionally, DFN is still a recent phenomenon that is largely confined to fringe 
websites visited by quite small and primarily very conservative audiences (Guess et al. 2018). Though again for the sake of parsimony we did not present the figures, we also found that only a small proportion of our sample regularly selectively attended to the prominent DFN purveyors Brietbart News and InfoWars, and these participants were strongly right-wing. Now, it is certainly possible that our limited one-shot experiment simply failed to capture what are otherwise plausible and significant main DFN exposure effects. However, we argue that taken together, all the interrelated factors and findings discussed above help to better explain why neither of the DFN treatment conditions induced direct aggregate effects on the candidate preferences of our diverse and fairly large treatment samples.

Regarding our secondary research objective, the interaction between DFN believability and partisan ideology did negatively affect evaluations of Clinton amongst conservative participants only. However, this moderated-mediated process did not significantly affect voting intentions for Clinton. Finally, the aforementioned interaction did not enhance the effects of the anti-Trump DFN treatment condition on evaluations of or voter support for Trump, which suggests that in these outcomes, there were no differences between leftists and conservatives. Overall, these findings are largely consistent with predictions and corroborate with recent studies, showing that even though people generally show a tendency to believe DFN about candidates from parties opposite to their own, belief susceptibility to DFN is predominantly a pronounced pathology of the right (Allcott and Gentzkow 2017; Guess et al. 2018; Mele et al. 2017; Pennycook and Rand 2019).

Furthermore, our findings suggest that compared to leftists, conservatives more regularly consumed news from the DFN outlet Brietbart News; less regularly consumed news from major television news networks; and had lower levels of general political knowledge. It can be partially inferred from these and the other findings discussed that during instances of exposure to DFN about a rival candidate, conservatives are less likely to have relevant accurate or counter information ready at their disposal. They are, therefore, more likely to automatically rely on heuristic cues and gut feelings to process the presented information. The end result being a greater acceptance and incorporation of the communicator prescribed judgements and interpretations into their existing partisan schema networks. By this same token, conservatives would also be more motivated and likely to reject the claims of DFN content with opinion-challenging information. In contrast, leftists are prone to employing systematic processing when assessing political stimuli (Jost and Krochik 2014; Pennycook and Rand 2019). This enables them to draw on their relevant and often more accurate stores of knowledge when considering the veracity of DFN content, such that they are better able to discern fake news about candidates that are congenial or uncongenial to their partisan beliefs and attitudes. And so, their subsequent evaluations of and decisions to vote or not to vote for a particular candidate are considerably less likely to be influenced by DFN. Whilst mode of cognitive processing was not measured by this study, the results are highly consistent with a growing body of experimental research on the ideological asymmetries in cognitive processing styles (e.g., Jost and Krochik 2014; Pennycook and Rand 2019; Shook and Fazio 2009).

In sum, this study contributes novel experimental evidence that extends the current research on DFN and democratic elections. Like this nascent research (e.g., Allcott and Gentzkow 2017; Guess et al. 2018; Nelson and Taneja 2018), our findings indicate that people's political predispositions strongly orient candidate evaluations and voting preferences, but these predispositions are currently unlikely to be meaningfully altered by attention to DFN. Instead, the effects of consuming DFN through either social media or dedicated fraudulent news sites seem likelier to be that of just confirming and reinforcing people's pre-existing views and biases. This may, consequently, potentiate voter turnout amongst people with strong partisan orientations and allegiances, but our findings indicate that this potentiation is not likely to be significant. Hence, if our results and interpretations hold true for the population, they imply that the electoral impact of DFN is for now probably quite narrow in scope. Indeed, in the large majority of times, DFN consumption and sharing could simply function as echo-chamber and/ or venting mechanisms that allow online users-especially far-right ones, to get validation for their longstanding views and express their sociopolitical grievances to anyone that will listen. Moreover, such dispositional views and grievances have been most probably induced during their formative years via interactions with the traditional primary agents of political socialization, and cultivated thereafter. Thus, here, we also postulate that selective attention to DFN is possibly a symptom rather than a cause of ongoing ideological polarization. That said, this study is exploratory in nature, and so, the processes, inferences, and explanations outlined should be tested in future research.

\section{Limitations}

This study has strengths in its between-subject design with a control condition, cross-sectional treatment samples, and robust covariate controls. The web-survey format, realistic social media and online news simulations, and non-laboratory setting also combined to enhance this study's ecological validity. Nevertheless, due to the political nature of the questionnaire, this study's results are susceptible to a social desirability response bias. Additionally, even though the treatment stimuli were masked as reading tasks and placed 
in between several distractor questions, participants were made to directly attend to the DFN materials. Therefore, there is a possibility that some participants realized the purpose of the study and corrected their biases when answering the outcome measures. Also, like all one-shot media experiments, this study cannot gage longitudinal effects, and it may be that DFN exposure directly affects attitude and behavioral intent changes after multiple sessions and/or at different dosage thresholds. Thus, research utilizing a longitudinal or repeated-measures design, varying but subliminal or less obvious DFN exposure conditions, and implicit attitudinal measures are needed to verify the findings from this exploratory research.

Finally, Trump and Clinton were the most disliked candidates in US polling history, and both were viewed almost equally negatively by our participants. Hence, DFN exposure may affect stronger changes in attitudes and voting intentions towards less well-known and polarizing candidates. Additionally, this study only focused on DFN related specifically to US candidate presentations, and so cannot speak to the potential electoral impact of DFN in other countries; nor, to the effects of DFN about hot-topic political issues and policies-which may have a more potent influence on voter decisions. Therefore, DFN should continue to be viewed with concern and researched in other national and political contexts, particularly in nations currently experiencing increasing public support for right-wing populism.

Open Access This article is licensed under a Creative Commons Attribution 4.0 International License, which permits use, sharing, adaptation, distribution and reproduction in any medium or format, as long as you give appropriate credit to the original author(s) and the source, provide a link to the Creative Commons licence, and indicate if changes were made. The images or other third party material in this article are included in the article's Creative Commons licence, unless indicated otherwise in a credit line to the material. If material is not included in the article's Creative Commons licence and your intended use is not permitted by statutory regulation or exceeds the permitted use, you will need to obtain permission directly from the copyright holder. To view a copy of this licence, visit http://creativecommons.org/licenses/by/4.0/.

\section{Appendix}

\section{Anti-Clinton DFN examples}

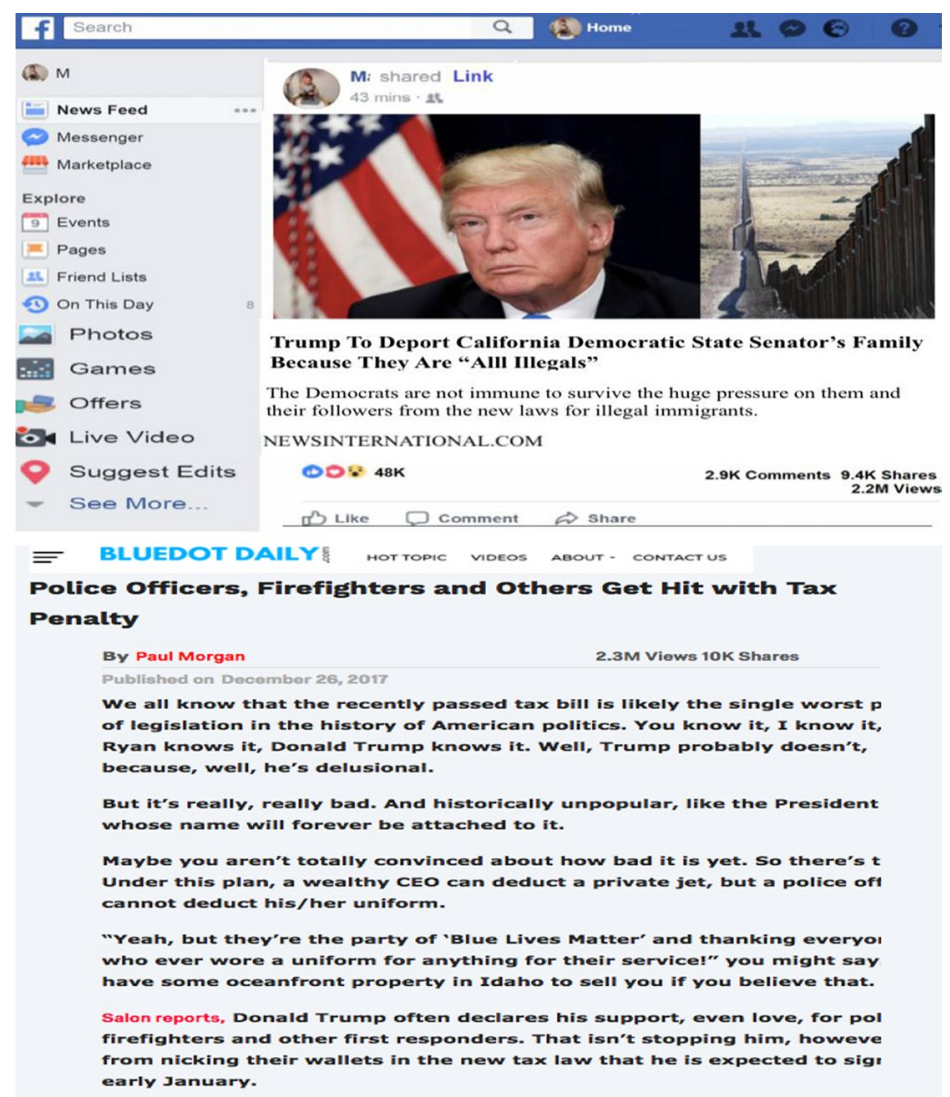




\section{Anti-Trump DFN examples}

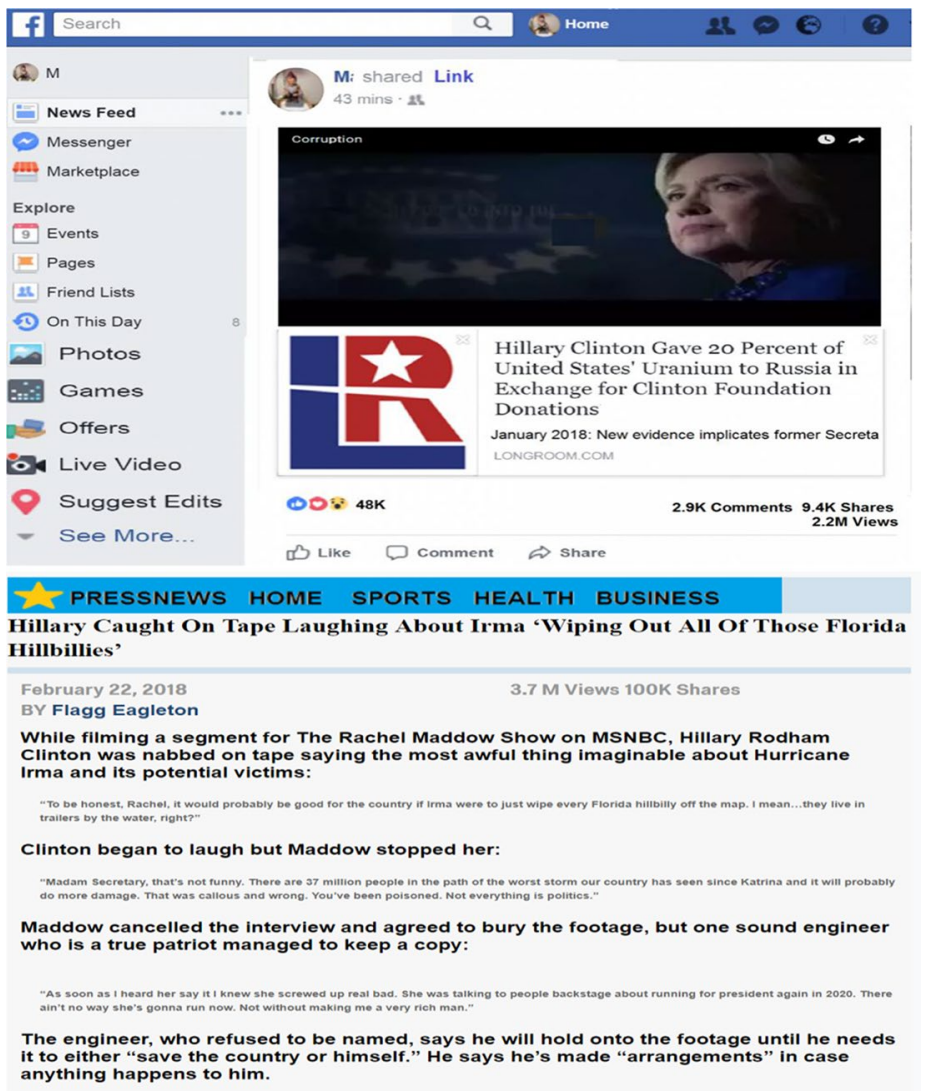

\section{References}

Allcott H, Gentzkow M (2017) Social media and fake news in the 2016 election. J Econ Perspect 31:211-236. https://doi.org/10.3386/ w23089

Arendt F (2013) News stereotypes, time, and fading priming effects. J Mass Commun Q 90:347-362. https://doi.org/10.1177/10776 99013482907

Arnaudo D (2017) Computational propaganda in Brazil: social bots during elections. Computational propaganda project working paper series. https://www.comprop.oii.ox.ac.uk/2017/06/19/ computational-propaganda-in-brazil-social-bots-during-elections/. Accessed 3 Apr 2019

Arpan LM, Raney AA (2003) An experimental investigation of news source and the hostile media effect. J Mass Commun Q 80:265281. https://doi.org/10.1177/107769900308000203

Balmas M, Sheafer T (2010) Candidate image in election campaigns: attribute agendasetting, affective priming, and voting intentions. Int J Public Opin Res 22:204-229. https://doi.org/10.1093/ijpor ledq009

Baumgartner SE, Wirth W (2012) Affective priming during the processing of newsarticles. Media Psychol 15:1-18. https://doi. org/10.1080/15213269.2011.648535

Borah P (2011) Conceptual issues in framing theory: a systematic examination of a decade's literature. J Commun 61:246-263. https ://doi.org/10.1111/j.14602466.2011.01539.x

Brader T, Valentino NA, Suhay E (2004) Seeing threats versus feeling threats: groupcues, emotions and activating opposition to immigration. Paper presented at the annual meeting of the American Political Science Association, Chicago, EEUU

Castillo W (2016) How we voted - by age, education, race and sexual orientation. USAToday, 9 November. https://college.usatoday. com/2016/11/09/how-we-votedby-age-education-race-and-sexua 1-orientation/. Accessed 1 Nov 2017

Chang C (2001) The impacts of emotion elicited by print political advertising on candidate evaluation. Media Psychol 3:91-118. https://doi.org/10.1207/S1532785XMEP0302_01

Ecker UK, Lewandowsky S, Chang EP, Pillai R (2014) The effects of subtle misinformation in news headlines. J Exp Psychol Appl 20:323-335. https://doi.org/10.1037/xap0000028

Feldman L (2011) The opinion factor: the effects of opinionated news on information processing and attitude change. Polit Commun 28:163-181. https://doi.org/10.1080/10584609.2011.565014

Friedersdorf C (2017) Breitbart's Astonishing Confession. The Atlantic. https://www.theatlantic.com/politics/archive/2017/12/theongoingmistreatment-of-right-leaning-news-consumers/54933 5/. Accessed 12 Dec 2017

Garrett RK (2009) Echo chambers online? Politically motivated selective exposure among Internet news users. J Comput Med Commun 14:265-285. https://doi.org/10.1111/j.1083-6101.2009.01440.x

Gibbons AJ, Lukowski FA, Walker R (2005) Exposure increases the believability of unbelievable news headlines via elaborate cognitive processing. Media Psychol 7:273-300. https://doi. org/10.1207/S1532785XMEP0703_3

Graf J, Aday S (2008) Selective attention to online political information. J Broadcast Electron Media 52:86-100. https://doi. org/10.1080/08838150701820874 
Guess A, Nyhan B, Reifler J (2018) Selective exposure to misinformation: evidence from the consumption of fake news during the 2016 US presidential campaign. https://www.dartmouth.edu/ nyhan/ fake-news-2016.pdf. Accessed 1 Nov 2018

Gutsche TL, Kapteyn A, Meijer E, Weerman B (2014) The RAND continuous 2012 presidential election poll. Public Opin Q 78:233254. https://doi.org/10.1093/poq/nfu009

Haciyakupoglu G, Hui JY, Suguna VS, Leong D, Rahman MFBA (2018) Countering fake news: a survey of recent global initiatives. Singapore, RSIS

Haider-Markel DP, Joslyn MR (2001) Gun policy, opinion, tragedy, and blame attribution: the conditional influence of issue frames. J Polit 63:520-543. https://doi.org/10.1111/0022-3816.00077

Hayden ME (2018) How 'The Storm' became the biggest fakes news story of 2018. Newsweek. https://www.newsweek.com/how-storm -biggest-fakenews-story-796725. Accessed 5 Feb 2018

Hayes AF (2013) Introduction to mediation, moderation, and conditional process analysis: a regression-based approach. Guilford Press, New York

Igartua JJ, Cheng L (2009) Moderating effect of group cue while processing news on immigration: is the framing effect a heuristic process? J Commun 59:726-749. https://doi.org/10.111 1/j.1460-2466.2009.01454.x

Igartua JJ, Moral-Toranzo F, Fernández I (2012) Cognitive, attitudinal, and emotional effects of news frame and group cues, on processing news about immigration. J Media Psychol 23:174-185. https ://doi.org/10.1027/1864-1105/a000050

Johansen MS, Joslyn MR (2008) Political persuasion during times of crisis: the effects of education and news media on citizens' factual information about Iraq. J Mass Commun Q 85:591-608. https:// doi.org/10.1177/107769900808500307

Jost JT, Krochik M (2014) Ideological differences in epistemic motivation: implications for attitude structure, depth of information processing, susceptibility to persuasion, and stereotyping. Adv Motiv Sci 1:181-231. https://doi.org/10.1016/bs.adms.2014.08.005

Kim K, McCombs M (2007) News story descriptions and the public's opinions of political candidates. J Mass Commun Q 84:299-314. https://doi.org/10.1177/107769900708400207

Knobloch-Westerwick S, Meng J (2011) Reinforcement of the political self through selective exposure to political messages. J Commun 61:349-368. https://doi.org/10.1111/j.1460-2466.2011.01543.x

Lecheler S, De Vreese CH (2011) Getting real: the duration of framing effects. J Commun 61:959-983. https://doi.org/10.111 1/j.1460-2466.2011.01580.x

Maniaci MR, Rogge RD (2014) Caring about carelessness: participant inattention and its effects on research. J Res Pers 48:61-83. https ://doi.org/10.1016/j.jrp.2013.09.008

Matthes J, Schmuck D (2017) The effects of anti-immigrant rightwing populist ads on implicit and explicit attitudes: a moderated mediation model. Commun Res 44:556-581. https://doi. org/10.1177/0093650215577859

Mele N, Lazer D, Baum M, Grinberg N, Friedland L, Joseph K, Mattsson $C$ (2017) Combating fake news: an agenda for research and action. https://www.northeastern.edu/nulab/wp-content/uploa ds/2017/04/Combating-Fake-NewsAgenda-for-Research.pdf. Accessed 1 Dec 2017
Miller JM, Krosnick JA (2000) News media impact on the ingredients of presidential evaluations: politically knowledgeable citizens are guided by a trusted source. Am J Polit Sci 44:301-315. https:// doi.org/10.2307/2669312

Moy P, Tewksbury D, Rinke EM (2016) Agenda-setting, priming, and framing. In: Donsbach W (ed) The international encyclopaedia of communication theory and philosophy. Blackwell, Oxford

Mustafaraj E, Metaxas PT (2017) The fake news spreading plague: was it preventable? Cornell University Library. arXiv:1703.06988 [cs.SI]

Nelson JL, Taneja H (2018) The small, disloyal fake news audience: the role of audience availability in fake news consumption. New Media Soc 20:3720-3737. https://doi.org/10.1177/1461444818 758715

Newton K (2019) Surprising news: how the media affect, and do not, affect politics. LynneRienner Publishers, Incorporated, Boulder

Pennycook G, Rand DG (2019) Lazy, not biased: susceptibility to partisan fake news is better explained by lack of reasoning than by motivated reasoning. Cognition 188:39-50. https://doi. org/10.1016/j.cognition.2018.06.011

Pennycook G, Rand DG (2018) Crowdsourcing judgments of news source quality. https://papers.ssrn.com/sol3/papers.cfm?abstr act_id=3118471. Accessed 3 Mar 2019

Pennycook G, Cannon TD, Rand DG (2017) Prior exposure increases perceived accuracy of fake news. https://ssrn.com/abstract=29582 46. Accessed 1 Jan 2018

Petersen MB, Skov M, Serritzlew S, Rams $\varnothing$ y T (2013) Motivated reasoning and political parties: evidence for increased processing in the face of party cues. Polit Behav 35:831-854. https://doi. org/10.1007/s11109-012-9213-1

Seate AA, Mastro D (2017) Exposure to immigration in the news: the impact of group level emotions on intergroup behavior. Commun Res 44:817-840. https://doi.org/10.1177/0093650215570654

Shook NJ, Fazio RH (2009) Political ideology, exploration of novel stimuli, and attitude formation. J Exp Soc Psychol 45:995-998. https://doi.org/10.1016/j.jesp.2009.04.003

Slothuus R, De Vreese CH (2010) Political parties, motivated reasoning, and issue framing effects. J Polit 72:630-645. https://doi. org/10.1017/S002238161000006X

Tandoc EC, Lim ZW, Ling R (2017) Defining "Fake News" a typology of scholarly definitions. Digit J. https://doi.org/10.1080/21670 811.2017.1360143

Vargo CJ, Guo L, Amazeen MA (2018) The agenda-setting power of fake news: a big data analysis of the online media landscape from 2014 to 2016. New Media Soc 20:2028-2049. https://doi. org/10.1177/1461444817712086

Vaske JJ, Donnelly MP (1999) A value-attitude-behavior model predicting wildland preservation voting intentions. Soc Nat Resour 12:523-537. https://doi.org/10.1080/089419299279425

Publisher's Note Springer Nature remains neutral with regard to jurisdictional claims in published maps and institutional affiliations. 